\title{
Enhancing Workforce Readiness of Engineering Technicians
}

\author{
Christine Delahanty, Vladimir Genis, Susan Herring, Tracy Timby
}

Bucks County Community College in collaboration with Drexel University will utilize funds from an NSF ATE grant to develop and integrate and innovative teaching model designed to prepare future technicians for industry by incorporating soft skills training, career exploration, and entrepreneurship. This collaborative model will formally connect the Bucks Center for Workforce Development (CWD) sector with our for-credit engineering technology program, our Business and Innovation Department, and with our educational and industry partners. This innovative project will enable our college to strengthen our technician education programs, formalize connections with CWD and our Business and Innovation Department, and prepare students for industry jobs through shadowing opportunities, employment, entrepreneurship, internships, and real-world, collaborative outreach. Our community college will collaborate with our Industry Advisory Board (IAB), CWD, and educational partners to (a) integrate an innovative teaching model for technician education that includes a formalized shadowing and internship program and connects students to opportunities in business and entrepreneurship. (b) require students to take a manufacturing laboratory course to introduce hands-on industry-related experiences; (c) include certifications that award digital badges, credit for military training, and industry experience in our engineering technology program. It is our intention that this model for an enhanced educational experience designed to increase workforce readiness of students will become a blueprint for other programs and institutions.

There is an urgent and growing need for workforce ready technicians to fill industry roles. The Bureau of Labor Statistics (BLS) indicated that the job outlook for mechanical and civil engineering technicians showed a 3\% and 5\% increase respectively in the 10-year span from 20182028 , where the median salary is over $\$ 50,000$ [2]. An innovative plan must be developed to assure that the number of students enrolled in surrounding for-credit Tech Ed programs increases, and that increasing retention and graduation rates is a priority [3]. A solution to this problem is rooted in our Center for Workforce Development (CWD) and in soft skills training through our CWD, and our Business and Innovation Department. In order to increase the number of engineering technicians in our region, Bucks County Community College (Bucks) in collaboration with Drexel University, is utilizing funds from an NSF ATE grant to collaborate with our Center for Workforce Development (CWD) and our Business and Innovation Department to create an enhanced curriculum for engineering technology ENGT majors. This will lead to increasing the number of students obtaining degrees in science, technology, engineering, and mathematics (STEM) fields. Increasing the number of graduates will, in turn, "provide a workforce that is prepared to ensure a healthy economy, respond to demands of national security, and maintain and elevate the quality of life.

The non-credit programs at Bucks provide high-value training and certifications that prepare individuals to enter directly into the workforce upon program completion. The CWD has grown at an impressive rate in recent years, and recently announced plans to build a new manufacturing facility at the college's lower campus. Our CWD has completed 22 cohorts of metalwork training, and 11 cohorts of industrial maintenance training, and has graduated 288 students, and boasts a $92 \%$ job placement rate. These programs have helped to shine a spotlight on the workforce challenges affecting our region. Our CWD Metalwork and Industrial Maintenance Training Programs recently achieved status as registered pre-apprenticeship programs with the state. The success of these programs has resulted in an increase in business participation by over $300 \%$, securing hundreds of thousands of dollars in grant funding, and was key in cementing 
relationships between the college, manufacturers, local and state government, and the Workforce Development system.

Our county expects to see nearly 3,000 new jobs in advanced manufacturing in the next 10 years. This, coupled with impending retirements of baby-boomers, makes it vitally important to provide accessible means for entry into the industry sector. The ability of CWD's program graduates to seamlessly transition into a technical degree program at our college will provide a pathway for students to earn a degree while working in the industry. The credits that can be applied towards a degree will incentivize CWD students to continue their education, thus building the number of skilled technicians in the region. When developing our certification, and our for credit programs, our industry and manufacturing partners made it abundantly clear that the most important skills for success on the job are to show up to work every day, on time, ready to work, and have the ability to communicate well with co-workers. In light of industry feedback, the program was designed to fully integrate soft skills, or employability skills, with the technical training, and includes industry certifications in OSHA 10 and Forklift Safety, strict attendance and punctuality requirements, a strong soft skills component, and 6-8 company tours per cohort. In addition, CWD provides a dedicated job developer who works closely with each student to ensure they are connected with good-fit jobs.

Our Business and Innovation Department is known for its dynamic programs and courses, and for its community outreach programs designed to better prepare students for the workforce. The department recently launched a co-curricular program designed to help a student find and participate in activities on campus, throughout the county and surrounding region. Students earn points for activities, event attendance, and accomplishments at varying levels. The program focuses on competency areas including soft-skills that employers are looking for: Community Engagement, Financial Literacy, Global Awareness, and Personal/Professional Development. The formalized collaboration with our Business and Innovation Department through this NSF grant, will allow us to incorporate the successes of their department into the development of a modernized curriculum that will prepare students for the future of industry.

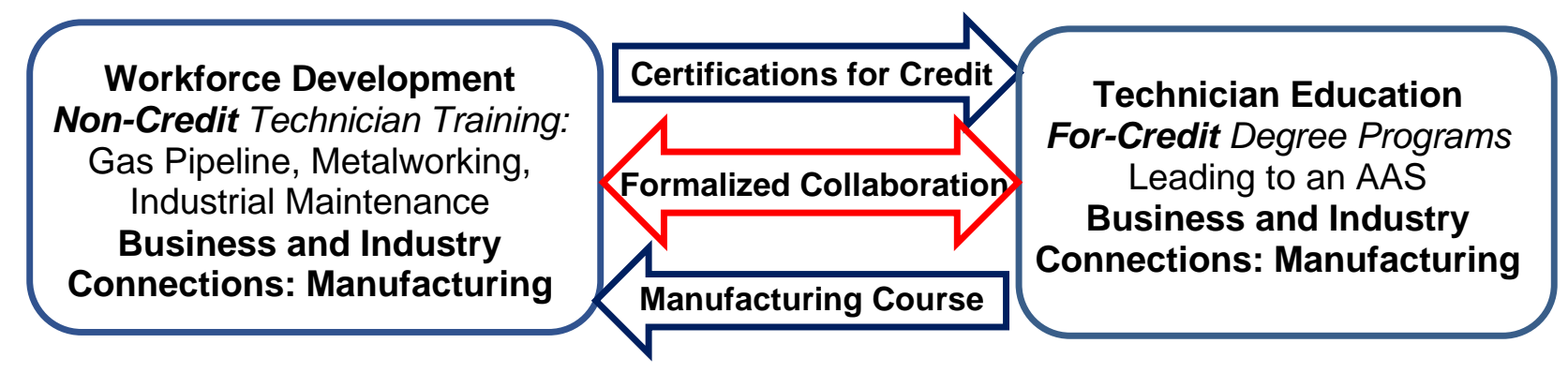

Figure 1. Collaborative model for technician education.

Through a formalized connection between our two sectors of the college, the credit and noncredits sides, the goal is to modernize the educational experience for our students to assure they are more workforce ready by establishing a model curriculum that will become a blueprint for 
other institutions. Figure 1 depicts our collaborative model, that connects our credit side to our CWD, and highlights manufacturing.

We routinely receive solicitations from surrounding companies reaching out to our community college for technicians to fill internships and job openings, and it is important that we meet this growing demand. Our Industry Advisory Board (IAB) members for our engineering technology program, have indicated to us at recent meetings that they are seeking technicians and interns that have the necessary soft skills training. Company executives have raised concerns that many of the younger employees they have hired recently do not arrive to work on time, do not show up for work regularly, and some "do not even know how to use a ruler." They have verbalized to us that the soft skills that incoming young employees need include "a willingness to learn," "flexibility with respect to shift," "regular attendance," "clean cut appearance," "passing a drug test," and "knowing how to communicate." Basic "hard skills" include "knowing how to use a basic tools and instruments," "not being afraid to turn knobs," and "being able to fix something independently,"

Members of our IAB have indicated that they will be able teach incoming technicians and interns the specific skills of the job more effectively if they encompass these very basic qualities. This soft skills gap that is a concern of our IAB, is shared by industry managers and executives nationwide. An announcement by CBS Moneywatch on May 17, 2016 indicated that "According to a survey released today by PayScale, which provides data on salaries, and executive development firm Future Workplace... More than half of all companies (60\%) said new grads lacked critical thinking skills and attention to detail (56\%), while $40 \%$ found fault with their writing proficiency, and 39\% were critical of their public speaking ability." [1]

In order to better understand challenges in preparing students for the workforce, we conducted round table sessions with faculty from our community college, and at the 2019 NSF ATE PI conference to help to answer the two questions, "What do our students need to become more workforce ready?" and "What can we do as educators to help students become more workforce ready?"

Some of the responses to the question "What do YOU THINK students need to become more workforce ready???" were:

- Persistence

- Experience through internships

- Know how to write a memo letter etc.

- Think and problem solve

- Confidence to learn on the job

- Learn how to think

- Open to criticism and suggestions for improving

- Sense of responsibility and ownership

- Oral and written communication skills

- Know how to ask questions and find the answers

- Clear understanding of what is expected of them 
- Respect for themselves and for authority

- Be able to do things without technology

Being able to communicate was discussed as being the most important skill that students needed to become more workforce ready.

Some of the responses to "What can WE do as educators to help students become more workforce ready???" were:

- Use the college's Student Research Conference for collaborative open ended problems

- Don't hesitate to give an F for F work

- Reinforce soft skills through engagement

- More humanities education

- More internships

- Talk about skills to be acquired in courses

- Improve Communication

- Help students learn to take critique positively

- Enforce class and assignment requirements

- Challenge students with high expectations and provide honest feedback

- Offer competitive team assignments

- Give them work related experiences: role play and team projects

- Have them fix their errors

- Stress that the skills they are learning will help to qualify them for jobs

Our plan is to better enhance the experience of students through workforce training as part of curricula. Through this formalized collaboration of our two college sectors and departments, and of our four year institution, Drexel University, emphasis will be placed on utilizing the resources from our CWD certification programs to accept their credits for transfer into our engineering technology Associate degree program, to offer soft-skills training and career exploration opportunities through CWD, including guided tours of local companies, a shadowing program, and to offer our credit students opportunities to use the CWD manufacturing equipment and facilities. We plan to mimic the robust and individualized soft-skills training and job placement opportunities of our CWD with our ENGT majors. ENGT students will be invited to accompany CWD students on company tours, and join in on training components that result in industry recognized certifications. The additional certifications, in which the students will earn digital badges, will not only enhance students' resumes, but will better prepare them for work in the industry.

Curriculum enhancements to our engineering technology program will include:

1. establishing a cohort of incoming engineering technology students for our Introduction to College course, which will include soft skills training, career exploration, and job shadowing,

2. requiring all technician education majors to take a business elective course, such as management, accounting, or entrepreneurship,

3. requiring students to take a manufacturing lab course, 
4. increasing flexibility in choosing electives, where specialized concentrations will include options such as mechanical, civil, biomedical, and nanotechnology,

5. allowing students with CWD certifications to gain credit for them within the engineering technology major,

6. accepting for college credit certain certifications and courses through high school engineering technology programs to offer a pathway into the engineering technology major,

7. offering a free elective that will allow students to use their internships completed through our IAB, CWD, or our Center for Student Development and Career Services, for course credit.

The goal is to pilot this modernized program at our college and measure student success to illustrate how our enhanced model will help to better prepare our technicians and our college for the future of industry. We will closely monitor this enhanced program, assess progress, and report outcomes, so that our learning model becomes a blueprint for community colleges nationwide. By continuing to offer soft skills training, enrichment opportunities, and career exploration, to our students, we will assure that they are better prepared for the workforce. Through this model, we will further extend our vision of broadening awareness of the importance of STEM careers, and specifically in fields that require skilled technicians. This innovative teaching model will ultimately benefit not only Bucks County Community College, but also the people, educational institutions, and businesses in the surrounding region and beyond.

Acknowledgement-This work is supported by the NSF Grant \# 1902075 "Increasing the Number of Workforce-ready Engineering Technicians in Southeastern Pennsylvania."

\section{References}

[1] Berr, Jonathon. Employers: New college grads aren't ready for workplace. Moneywatch. (May 2016). Retrieved from https://www.cbsnews.com/news/employers-new-college-grads-arent-ready-for-workplace/

[2] Bureau of Labor Statistics (BLS): Occupational Outlook Handbook. (2019). Retrieved from https://www.bls.gov/ooh/architecture-and-engineering/home.htm

[3] Taraban, R., Ceja, M., Suarez, J., Ernst, D., \& Anderson, E. E. (2018). Building an engineering technology workforce. Journal of Engineering Technology, 35(1), 30-38. 